\title{
Balanço de cálcio e fósforo e estudo dos níveis desses minerais em dietas para codornas japonesas (45 a 57 semanas de idade)
}

\section{Carlos Henrique Rocha Costa ${ }^{1}$, Sergio Luiz de Toledo Barreto ${ }^{2}$, Regina Tie Umigi ${ }^{3}$, Heder José D`Avila Lima ${ }^{3}$, Marcelle Santana de Araujo ${ }^{3}$, Paola Medina ${ }^{4}$}

\author{
${ }^{1}$ Doutorando em Zootecnia da Universidade Federal de Viçosa. \\ 2 Universidade Federal de Viçosa - Departamento de Zootecnia, s/n-Campus Universitário - Viçosa, MG. \\ ${ }^{3}$ Doutorando em Zootecnia na Universidade Federal de Viçosa. \\ ${ }^{4}$ Graduando em Zootecnia na Universidade Federal de Viçosa.
}

RESUMO - Objetivou-se verificar o efeito de quatro níveis de cálcio (Ca) e de fósforo disponível (Pd) na dieta sobre o desempenho, a qualidade dos ovos e a excreção mineral em codornas japonesas durante o terço final do ciclo de produção Utilizaram-se 384 codornas, com 313 dias de idade, distribuídas em delineamento inteiramente casualizado em esquema fatorial $4 \times 2$, composto de quatro níveis de cálcio $(2,0 ; 2,5 ; 3,0$ e 3,5\%) e dois de fósforo disponível (0,15 e 0,35\%), de modo que cada combinação foi avaliada em seis repetições de oito aves. As dietas experimentais foram isoproteicas (19,31\% de PB), isocalóricas $(2.800 \mathrm{kcal}$ de $\mathrm{EM} / \mathrm{kg}$ ) e isoaminoacídicas. Foram avaliados a produção, o peso, a massa, a altura e o diâmetro dos ovos, o consumo de ração, a conversão alimentar, a viabilidade, o peso específico, os componentes dos ovos (peso e porcentagem de casca, albúmem e gema), o balanço de cálcio e fósforo total e a excreção de matéria mineral. Não houve interação dos níveis de cálcio e fósforo disponível utilizados. O aumento do nível de cálcio na dieta melhorou linearmente a conversão por dúzia e reduziu o consumo. Promoveu também aumento no peso específico, no peso e na porcentagem de casca e redução linear no peso da gema e aumentou o teor de cálcio nas excretas. A viabilidade e o teor de fósforo nas excretas aumentaram com o acréscimo de fósforo disponível, enquanto as demais variáveis não foram influenciadas pelos níveis de cálcio e fósforo disponível da dieta. Os níveis de 3,5\% de cálcio e o de 0,15\% de fósforo disponível são suficientes para proporcionar bom desempenho produtivo e manutenção satisfatória da qualidade dos ovos de codornas japonesas no terço final de postura (45 a 57 semanas de idade), e correspondem a consumos diários de 899 mg de cálcio e 40 mg de fósforo disponível por ave.

Palavras-chave: conversão alimentar, Coturnix coturnix japonica, desempenho, nível nutricional, qualidade do ovo, viabilidade

\section{Balance of calcium and phosphorus and study of these minerals in diets for Japanese quails (from 45 to 57 weeks of age)}

\begin{abstract}
This experiment was conducted aiming to verify the effect of four levels of calcium (Ca) and available phosphorus (aP) in the diet on the performance, quality of eggs and the mineral excretion in Japanese quails during the final third of the production cycle. A total of 384 quails at 313 days of age was used. They were distributed in a complete random design in a $4 \times 2$ factorial scheme composed of four levels of calcium (2.0, 2.5, 3.0, and 3.5\%) and two levels of available phosphorus (0.15 and $0.35 \%)$, so each combination was evaluated in six replicates of eight birds. The experimental diets were isoprotein $(19.31 \% \mathrm{CP})$, isocaloric $(2,800 \mathrm{kcal} / \mathrm{kg})$ and isoaminoacids. It was evaluated the production, weight, mass, height and diameter of the eggs, ration consumption, feed conversion, viability, specific weight, the components of eggs (weight and percentage of shell, albumen and yolk), the balance of calcium and total phosphorus and excretion of mineral matter. There was no interaction between the used levels of calcium and available phosphorus. The increase in the level of calcium in the diet linearly improved the conversion by dozen and it reduced the consumption. It also promoted an increase on the specific weight, on the weight and on the percentage of shell and linear reduction on the weight of yolk and it increased the calcium content in the excreta. The viability and content of phosphorus in the excreta increased as the available phosphorus increased, whereas the other variables were not influenced by the levels of calcium and available phosphorus in the diet. The levels of $3.5 \%$ of calcium and $0.15 \%$ of available phosphorus are sufficient to provide good productive performance and satisfactory maintenance of the quality of eggs of Japanese quails in the final third of laying (45 to 57 weeks of age), and they correspond to a daily consumption of $899 \mathrm{mg}$ of calcium and $40 \mathrm{mg}$ of available phosphorus per bird.
\end{abstract}

Key Words: Coturnix coturnix japonica, egg quality, food conversion, nutritional level, performance, viability 


\section{Introdução}

As pesquisas na área de nutrição de codornas estão concentradas em temas relevantes, mas pouco diversificados. Na área de nutrição, maior número de trabalhos foi realizado para estimar as exigências de proteína, energia, aminoácidos sulfurados, lisina e cálcio (Silva et al., 2007). Entretanto, pouco destaque se deu à treonina, o segundo aminoácido limitante na ração de codornas, ao fósforo, mineral que mais onera o custo da ração, aos minerais traços e às vitaminas.

Os minerais cálcio e P estão totalmente comprometidos com a produtividade das aves, atuando em várias funções metabólicas vitais para a vida destas. De acordo com Leandro et al., (2006), a margem de lucro dos produtores de ovos de codornas e poedeiras comerciais muitas vezes é comprometida por problemas associados à qualidade da casca. Sabe-se que a quantidade de cálcio depositada na casca não varia tão substancialmente com a idade, porém o tamanho do ovo aumenta, aumentando a sua fragilidade.

Como são muitos os fatores limitantes que interferem na determinação dos níveis de cálcio e de Pd, é comum na literatura a divergência entre os diversos autores quanto à suplementação desses minerais na dieta.

Conforme revisão realizada por Silva et al. (2007) sobre a exigência de cálcio para codornas japonesas em postura, Yakout (2004) recomenda até 3\%, Barreto et al. (2007) 3,2\%, Brandão et al. (2007) 3,51\%, Costa et al. (2007) 2,5\%, Kadam et al. (2006) e Sultana et al. (2007) recomendam $3 \%$ de cálcio para a fase de postura.

Quanto à exigência de $\mathrm{P}$, poucos artigos são encontrados na literatura sobre estimativas desse mineral para codornas (Silva et al. 2007). Entretanto, na fase de produção, Yakout (2004) sugere de 0,35\% a 0,40\% e na fase inicial de postura (61 a 145 dias) e Costa et al. (2007) sugerem $0,31 \%$ de fósforo disponível na dieta.

Cabe ressaltar que ainda não há estudos que indiquem exatamente qual seria a idade ideal para o descarte de um lote de codornas japonesas, recebendo dietas balanceadas em cálcio e fósforo disponível nos períodos inicial, intermediário e terço final de postura, e quais as exigências desses minerais para a manutenção da produção de ovos de qualidade no último período citado. Contudo, direcionou-se um estudo dos níveis de cálcio e de Pd, no qual se objetivou avaliar o efeito de ambos sobre o desempenho e a qualidade dos ovos produzidos, além de fornecer dados sobre o balanço do cálcio e do Pt no organismo de codornas japonesas no terço final do ciclo de produção.

\section{Material e Métodos}

O experimento foi realizado no setor de Avicultura do Departamento de Zootecnia da Universidade Federal de Viçosa, Minas Gerais, no período de janeiro a abril de 2008. Utilizaram-se 384 codornas japonesas (Coturnix coturnix japonica), em terço final de postura, com 313 dias de idade, durante os quatro períodos experimentais de 21 dias.

O delineamento experimental foi inteiramente ao acaso, em esquema fatorial $4 \times 2$, composto de oito tratamentos (quatro níveis de cálcio em combinação a dois níveis de fósforo disponível na dieta), com seis repetições e oito aves por unidade experimental. Foram formuladas oito dietas experimentais, isocalóricas, isoproteicas e isoaminoacídicas, à base de milho e farelo de soja, com cinco níveis 2,0; 2,5; 3,0 e 3,5\% de cálcio em combinação a dois níveis de fósforo disponível (0,15\% e 0,35\%), constituindo-se os tratamentos experimentais (Tabela 1).

As dietas foram formuladas para atender às exigências nutricionais das codornas, segundo recomendações preconizadas pelo NRC (1994), exceto para as exigências de metionina + cistina digestível, lisina digestível, treonina digestível, triptofano digestível e de energia metabolizável, que foram baseadas nas recomendações de Pinto et al. (2003a,b), Umigi et al. (2007), Pinheiro et al. (2008) e Moura et al. (2008), respectivamente.

Água e ração foram fornecidas à vontade ao longo de todo o período experimental.

As aves utilizadas no experimento tinham aproximadamente 45 semanas de vida, ou seja, já haviam saído da fase de pico de postura, e continuaram recebendo 17 horas de luz diária até o término do período experimental, quando já apresentavam 397 dias de idade (aproximadamente 57 semanas de vida).

Os parâmetros de desempenho foram avaliados pela produção média de ovos por ave-dia (\%) e por ave-alojada (\%), peso médio dos ovos (g), massa de ovos (g), consumo de ração (g de ração/ave-dia), conversão alimentar (g de ração por dúzia e por massa de ovos) e viabilidade (\%).

A análise das qualidade externa e interna dos ovos foi realizada por meio da produção de ovos viáveis por ave-dia ((tx de postura (\%) × total de ovos viáveis)/(n-0 total de ovos produzidos)) e por ave-alojada ((produção de ovos por ave-alojada (\%) $\times$ total de ovos viáveis)/(n- total de ovos produzidos)), o peso específico $\left(\mathrm{g} / \mathrm{cm}^{3}\right)$, peso da casca (g), porcentagem de casca (\%), peso de albúmem (g), porcentagem de albúmem (\%), peso de gema (g), porcentagem de gema (\%) e a altura e diâmetro dos ovos (mm).

O peso específico dos ovos foi determinado pelo método de flutuação salina, conforme metodologia descrita 
por Hamilton (1982). Nos $16^{\circ}, 17^{\circ}$ e $18^{\circ}$ dias de cada um dos quatro períodos experimentais de 21 dias, todos os ovos íntegros coletados foram imersos em soluções de $\mathrm{NaCl}$ com densidade variando de $1,055 \mathrm{~g} / \mathrm{cm}^{3}$ a $1,100 \mathrm{~g} / \mathrm{cm}^{3}$, com intervalos de $0,005 \mathrm{~g} / \mathrm{cm}^{3}$ entre elas, totalizando dez soluções, sendo o peso específico medido por meio de um densímetro.

Quatro ovos de cada unidade experimental foram coletados durante o 19ํㅜ $20^{\circ}$ e $21^{\circ}$ dias de cada período. Foram pesados individualmente em balança com precisão de $0,001 \mathrm{~g}$. Após as pesagens e escolha dos quatro ovos com peso próximo ao peso médio da respectiva unidade experimental, foram identificados e quebrados. A gema de cada ovo foi pesada, e a respectiva casca foi lavada e seca ao ar, para obtenção de seu peso; por diferença, obteve-se o peso do albúmen.
Ao término do experimento, separaram-se três unidades experimentais por tratamento para coleta total de excretas, a fim de se realizar o balanço dos minerais cálcio e Pt e quantificar o teor de cinzas ou matéria mineral das excretas. As rações foram pesadas no início e as sobras, no final do período de coleta, para posterior determinação do consumo alimentar. A coleta total das excretas iniciou-se após o período de adaptação, e era realizada duas vezes ao dia, às $8 \mathrm{~h}$ e às $17 \mathrm{~h}$, para evitar possível fermentação. As bandejas foram encapadas com plástico para facilitar a coleta e evitar perdas do material excretado.

As excretas recolhidas em cada unidade experimental, após eliminação de penas, resíduos de ração e outras fontes de contaminação, foram transferidas para sacos plásticos, previamente identificados e colocados em freezer até o final do ensaio de metabolismo. Posteriormente,

Tabela 1 - Composição em ingredientes e nutricional das dietas experimentais (\% matéria natural)

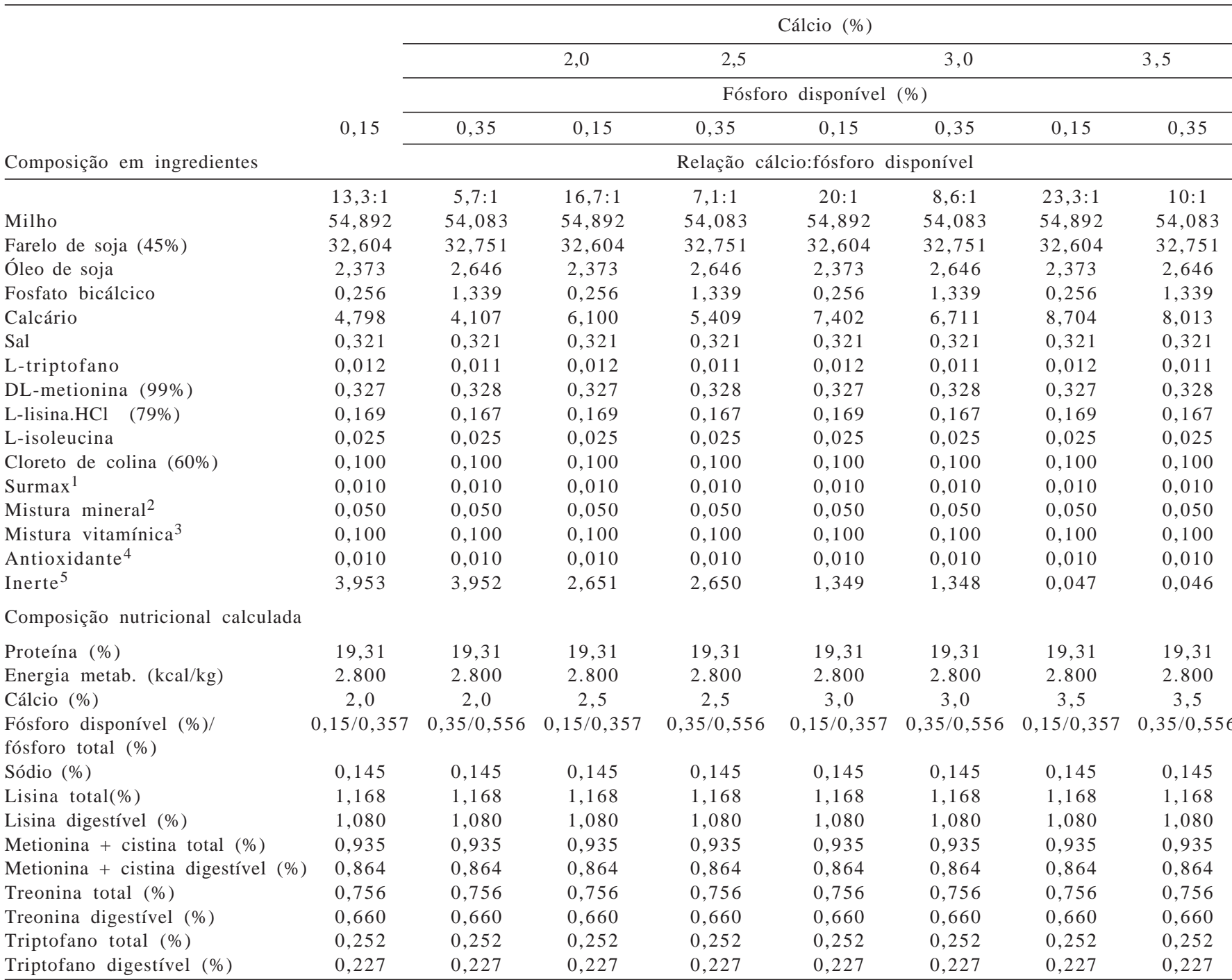

${ }^{1}$ Avilamicina (10\%).

${ }^{2}$ Composição/kg de produto: vit. A - 12.000 .000 U.I.; vit $D_{3}$ - 3.600 .000 U.I.; vit. E - 3.500 U.I.; vit $B_{1}$ - 2.500 mg, vit. $B_{2}$ - 8.000 mg; vit $B_{6}$ - 5.000 mg; ácido pantotênico - 12.000 mg; biotina - 200 mg; vit. K - 3.000 mg; ácido fólico - 1.500 mg; ácido nicotínico - 40.000 mg, vit. B 12 - 20.000 mg; selênio - 150 mg; veículo q.s.p. - 1.000 g.

${ }^{3}$ Composição/kg de produto: manganês - 160 g; ferro - 100 g; zinco - 100 g; cobre - 20 g; cobalto - 2 g; iodo: 2 g; excipiente q.s.p. - 1.000 g. ${ }^{4}$ Butil-hidróxi-tolueno; ${ }^{5}$ Areia lavada. 
as excretas foram descongeladas, pesadas e homogeneizadas, sendo retiradas alíquotas de 200 g a 210 g de cada repetição para pré-secagem, e colocadas em estufa de ventilação forçada, à temperatura de $55^{\circ} \mathrm{C}$, por um período de 72 horas. As amostras de excretas foram, então, moídas e submetidas às análises segundo metodologias descritas por Silva (1998).

Ao término do ensaio de metabolismo, determinou-se o consumo de ração e a quantidade total excretada.

Foi realizada a análise de variância a 5\% de probabilidade, utilizando-se o Programa SAEG - Sistema para Análises Estatísticas e Genética - UFV (2004). Posteriormente, os efeitos dos níveis de cálcio e de fósforo foram estimados por meio de análise das variáveis pelos modelos de regressão linear e quadrática, levando-se em consideração o comportamento biológico das aves.

\section{Resultados e Discussão}

Não houve interação entre os níveis de cálcio e fósforo disponível da dieta sobre nenhuma das variáveis estudadas, portanto os níveis de cálcio e de fósforo disponível comportaram-se de forma independente e as variáveis foram analisadas pelos seus efeitos principais (Tabelas 2, 3, 4 e 6).

Os diferentes níveis de cálcio testados nas dietas não influenciaram ( $\mathrm{P}>0,05)$, a produção média de ovos por ave-dia. Porém, observou-se que as aves que receberam maior nível de cálcio (3,5\% Ca) na dieta atingiram produção média equivalente a 81,9\% de postura no período de 313 a 397 dias de vida. Isso demonstra, em valores absolutos, uma produção de ovos aproximadamente 2,4\% superior à produção obtida por aves que receberam (2,0\% Ca) na dieta. Diferentemente, Brandão et al. (2007), testando sete níveis (2,95\% a 3,85\%) de cálcio na dieta de codornas japonesas

Tabela 2 - Desempenho de codornas japonesas alimentadas com dietas com diferentes níveis de cálcio

\begin{tabular}{|c|c|c|c|c|c|c|}
\hline \multirow[t]{2}{*}{ Item } & \multicolumn{4}{|c|}{ Nível de cálcio (\%) } & \multirow{2}{*}{$\begin{array}{l}\text { Valor } \\
\text { de P }\end{array}$} & \multirow[t]{2}{*}{$\mathrm{CV} \%$} \\
\hline & 2,0 & 2,5 & 3,0 & 3,5 & & \\
\hline Ovos/ave-dia (\%) & 79,53 & 80,69 & 81,20 & 81,91 & ns & 10,4 \\
\hline \multicolumn{7}{|l|}{ Ovos/ave- } \\
\hline alojada (\%) & 76,13 & 76,93 & 78,68 & 80,70 & ns & 11,5 \\
\hline Peso ovo (g) & 12,65 & 12,16 & 12,44 & 12,24 & ns & 3,3 \\
\hline Massa de ovos (g) & 10,14 & 9,68 & 10,10 & 9,94 & ns & 10,9 \\
\hline $\begin{array}{l}\text { Consumo de } \\
\text { ração }(g)^{1}\end{array}$ & 27,59 & 26,14 & 26,26 & 25,67 & $\mathrm{P}<0,01$ & 4,7 \\
\hline Conversão por & & & & & & \\
\hline massa de ovos (g) & 2,77 & 2,73 & 2,63 & 2,65 & ns & 10,2 \\
\hline Conversão por & & & & & & \\
\hline dúzia de ovos $(\mathrm{kg})^{1}$ & 0,420 & 0,391 & 0,389 & 0,381 & $\mathrm{P}<0,05$ & 10,1 \\
\hline Viabilidade (\%) & 89,58 & 91,67 & 90,62 & 95,83 & ns & 10,4 \\
\hline
\end{tabular}

em postura, só que mais novas do que as utilizadas nesse experimento, encontraram efeito quadrático dos níveis de Ca, sobre a produção de ovos ave-dia, sendo o valor máximo estimado com os níveis de 3,45\% de cálcio.

A produção média de ovos por ave-alojada não sofreu influência ( $\mathrm{P}>0,05)$ dos níveis de cálcio dietético, uma vez que a produção média de ovos por ave-dia e a viabilidade não variaram $(\mathrm{P}>0,05)$ diante dos quatro níveis de cálcio avaliados. Porém, pode-se constatar, em valores absolutos, que o maior nível de cálcio (3,5\%) testado proporcionou maior viabilidade às aves, cerca de 6,5\% na redução da mortalidade.

Ao se analisar o consumo de ração, constatou-se que os níveis de cálcio influenciaram $(\mathrm{P}<0,01)$ essa variável, onde aves que receberam o maior nível de cálcio (3,5\%) na dieta consumiram menor quantidade de ração quando comparado ao consumo obtido por aves que receberam níveis de suplementação inferiores. Tal resultado está de acordo ao encontrado por Garcia et al. (2000), os quais, estudando níveis de 2,5\% a 4,0\% de cálcio, observaram que níveis crescentes desse mineral provocaram redução linear no consumo de ração. De acordo com Garcia \& Pizzolante (2004), a elevação do nível de cálcio além de 2,5\% pode melhorar a qualidade da casca dos ovos, contudo poderá também haver redução no consumo de ração.

Os quatro níveis de cálcio estudados não influenciaram $(\mathrm{P}>0,05)$ o peso e a massa de ovos. Porém, cabe ressaltar aqui que o nível de 2,0\% de cálcio na dieta proporcionou às aves, em valores absolutos, produção de ovos de maior peso, e o nível de 3,5\% favoreceu a produção da maior massa de ovos.

Não foi verificado efeito dos níveis de cálcio sobre a conversão alimentar por massa de ovos. O mesmo foi obtido em pesquisa conduzida por Brandão et al. (2007) para a

Tabela 3 - Desempenho de codornas japonesas alimentadas com dietas com dois níveis de fósforo disponível

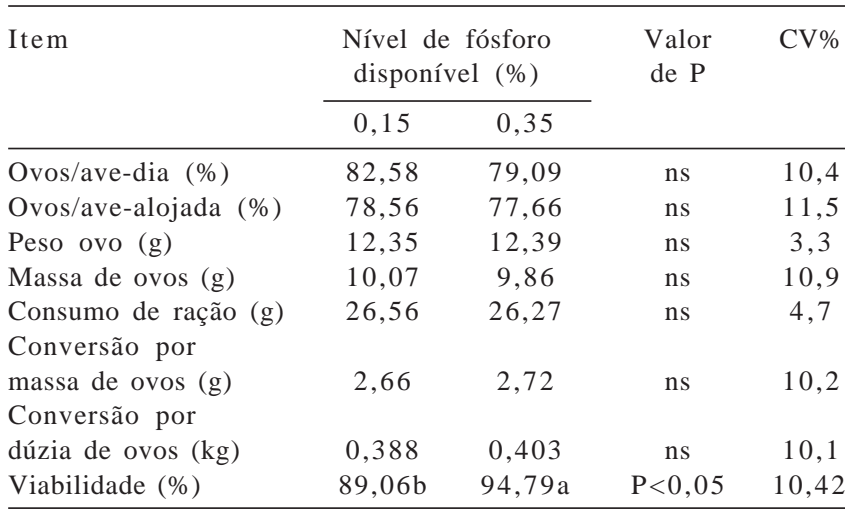

$\mathrm{ns}=$ não-significativo $(\mathrm{P}>0,05)$ 
variável mencionada. O contrário foi obtido por Barreto et al. (2007), que testando seis níveis de cálcio na ração (1,6 a 3,6\%) de 360 codornas japonesas durante o período inicial de produção (56 a 171 dias de idade) constataram redução linear para conversão alimentar por massa de ovos.

Houve efeito linear decrescente $(\mathrm{P}<0,05)$ ao se estudar a conversão alimentar por dúzia de ovos ( $\hat{Y}=0,461278$ $0,0238108 X ; R^{2}=0,81$ ), sendo que o melhor nível testado foi o correspondente a 3,5\% de cálcio (Tabela 3). Diferentemente desses achados, Pizzolante et al. (2007), trabalhando com escalonamento de oferta de cálcio para codornas em final de produção (54 semanas de idade), não encontraram diferenças $(\mathrm{P}>0,05)$ para consumo de ração e conversão alimentar por kg e por dz de ovos, concluindo que a variação dos níveis de cálcio durante os períodos considerados não alterou o desempenho produtivo das codornas.

Em trabalho conduzido por Masukawa et al. (2001) com codornas japonesas alimentadas com rações contendo quatro níveis de cálcio (2,0; 2,5; 3,0 e 3,5\%), também não houve diferenças $(\mathrm{P}>0,05)$ para consumo de ração, produção de ovos e peso médio dos ovos. Os pesquisadores concluíram que as codornas japonesas são tolerantes às variações de cálcio na dieta, sendo que o metabolismo delas permite adequar o nível de cálcio necessário à produção de ovos e excretar o excesso desse mineral, pelo menos dentro dos níveis testados. Diferentemente, Brandão et al. (2007)

Tabela 4 - Qualidade dos ovos e porcentagem de cálcio, fósforo e cinzas nas excretas de codornas japonesas alimentadas com dietas com diferentes níveis de cálcio

\begin{tabular}{|c|c|c|c|c|c|c|}
\hline \multirow[t]{2}{*}{ Item } & \multicolumn{4}{|c|}{ Nível de cálcio (\%) } & \multirow{2}{*}{$\begin{array}{l}\text { Valor } \\
\text { de P }\end{array}$} & \multirow[t]{2}{*}{ CV\% } \\
\hline & 2,0 & 2,5 & 3,0 & 3,5 & & \\
\hline $\begin{array}{l}\text { Ovos viáveis/ } \\
\text { ave-dia (\%) }\end{array}$ & 77,6 & 78,3 & 77,9 & 78,3 & ns & 11,1 \\
\hline $\begin{array}{l}\text { Ovos viáveis/ } \\
\text { ave-alojada (\%) }\end{array}$ & 74,2 & 74,7 & 75,5 & 77,2 & ns & 12,0 \\
\hline $\begin{array}{l}\text { Peso específico } \\
\left(\mathrm{g} / \mathrm{cm}^{3}\right)^{1} \\
\text { Peso de }\end{array}$ & 1,067 & 1,069 & 1,069 & 1,071 & $\mathrm{P}<0,01$ & 0,13 \\
\hline casca $(g)^{1}$ & 0,952 & 0,953 & 0,981 & 1,001 & $\mathrm{P}<0,01$ & 3,9 \\
\hline Casca $(\%)^{1}$ & 7,52 & 7,75 & 7,87 & 8,12 & $\mathrm{P}<0,01$ & 2,8 \\
\hline Peso de albúmen (g) & 7,74 & 7,47 & 7,65 & 7,57 & ns & 3,5 \\
\hline Albúmen (\%) & 60,96 & 60,74 & 60,96 & 61,40 & ns & 1,5 \\
\hline Peso de gema $(\mathrm{g})^{1}$ & 3,99 & 3,87 & 3,88 & 3,75 & $\mathrm{P}<0,01$ & 3,9 \\
\hline Gema (\%) & 30,99 & 31,38 & 30,90 & 30,50 & ns & 2,8 \\
\hline $\begin{array}{l}\text { Altura dos } \\
\text { ovos (mm) }\end{array}$ & 33,96 & 33,27 & 33,84 & 33,33 & ns & 1,7 \\
\hline Diâmetro dos & & & & & & \\
\hline $\begin{array}{l}\text { ovos }(\mathrm{mm}) \\
\text { Cálcio excretado }\end{array}$ & 25,81 & 25,53 & 25,57 & 25,58 & ns & 1,2 \\
\hline$(\%)^{1}$ & 2,86 & 3,51 & 4,55 & 5,51 & $\mathrm{P}<0,01$ & 9,2 \\
\hline P excretado (\%) & 1,12 & 1,10 & 1,16 & 1,10 & ns & 10,9 \\
\hline $\begin{array}{l}\text { Matéria mineral } \\
\text { excretada (\%) }\end{array}$ & 27,51 & 28,08 & 28,25 & 27,18 & ns & 3,5 \\
\hline
\end{tabular}

não encontraram efeito dos níveis de cálcio da dieta sobre o consumo de ração e conversão alimentar por massa de ovos. Os autores recomendam o nível de 3,51\% de cálcio na ração. Porém, Barreto et al. (2007) recomendam o nível de 3,2\% de cálcio na dieta como satisfatório para obtenção de melhor produção e eficiente conversão alimentar (por massa e por dúzia de ovos), e Costa et al. (2007), trabalhando com codornas no período de 61 a 145 dias de idade, recomendam o nível dietético de $2,5 \%$ de cálcio como sendo suficiente para proporcionar bom desempenho produtivo durante a fase inicial de postura.

Com o estudo dos níveis de fósforo disponível na dieta, observa-se que apenas a viabilidade das aves sofreu influência $(\mathrm{P}<0,05)$ e que o nível de $0,15 \%$ se mostrou melhor, em termos de valores numéricos $(\mathrm{P}>0,05)$, em quase todas as variáveis de desempenho analisadas, exceto para a variável mencionada anteriormente, tendo como satisfatório o maior nível testado (0,35\% Pd). Esse nível, quando comparado ao valor obtido pelo menor nível $(0,15 \% \mathrm{Pd})$, proporcionou aumento de $6,0 \%$ na viabilidade das aves. Também é importante mencionar que, apesar da não influência do fósforo disponível sobre a produção de ovos ave-dia, o nível de $0,15 \%$ proporcionou às aves produção 4,2\% superior ao obtido por aves que receberam o maior nível (0,35\%) na dieta.

A combinação entre os diferentes níveis de cálcio (2,5\%, 3,0\% e 3,5\%) e de fósforo disponível ( $0,25 \%, 0,45 \%$, $0,65 \%$ e $0,85 \%$ ) não proporcionou resultados significativos para percentagem de postura, consumo de ração, conversão alimentar e peso dos ovos, em pesquisa conduzida por Pedroso et al. (1999). Os autores recomendaram o nível de 0,45\% de fósforo disponível e 3,5\% de cálcio na dieta dessas aves.

Os diferentes níveis de cálcio não afetaram $(\mathrm{P}>0,05)$ a porcentagem de ovos viáveis ave-dia e viável ave-alojada, porém é conveniente ressaltar que o nível de 3,5\% de cálcio dietético proporcionou, em valores absolutos, a maximização de ambas as variáveis. O peso e a percentagem de albúmen,

Tabela 5 - Equações de regressão estimadas para os valores de desempenho (Y) e qualidade dos ovos (Y), em função do nível de suplementação de cálcio $(\mathrm{X})$ à dieta

\begin{tabular}{llc}
\hline Item & Regressão & $\mathrm{R}^{2}$ \\
\hline Consumo de ração & $\hat{Y}=29,5166-1,12766 \mathrm{X}$ & 0,78 \\
Conversão dúzia ovo & $\hat{Y}=0,461278-0,0238108 \mathrm{X}$ & 0,81 \\
Peso de gema & $\hat{Y}=4,26158-0,140169 \mathrm{X}$ & 0,88 \\
Peso de casca & $\hat{Y}=0,873907+0,0355951 \mathrm{X}$ & 0,91 \\
\% de casca & $\hat{Y}=6,76387+0,382608 \mathrm{X}$ & 0,98 \\
Gravidade específica & $\hat{Y}=1,06307+0,0021197 \mathrm{X}$ & 0,88 \\
\% de cálcio & & \\
excretado (MS) & $\hat{Y}=-0,843821+1,80078 \mathrm{X}$ & 0,99 \\
\hline
\end{tabular}

R. Bras. Zootec., v.39, n.8, p.1748-1755, 2010 
percentagem de gema, a altura e o diâmetro médio dos ovos e a percentagem de $\mathrm{P}$ e de matéria mineral excretada também não apresentaram diferenças $(\mathrm{P}>0,05)$ entre os níveis estudados. No entanto, os níveis de cálcio testados nas dietas influenciaram linearmente $(\mathrm{P}<0,01)$ o peso específico dos ovos, o peso de casca, a percentagem de casca e de cálcio nas excretas e o peso de gema.

Pedroso et al. (1999), testando a combinação entre três níveis de cálcio (2,5\%, 3,0\% e 3,5\%) e quatro níveis de fósforo disponível (0,25\%, 0,45\%, 0,65\% e 0,85\%), também perceberam influência sobre o peso específico dos ovos, com os níveis de $0,45 \%$ de fósforo disponível e 3,5\% de cálcio na dieta.

Esses dados diferem-se dos encontrados por Masukawa et al. (2001), os quais não encontraram diferenças ( $P>0,05)$ para peso específico dos ovos e percentagem de casca em suas experimentações, e dos obtidos por Pizzolante et al. (2007), que também observaram não haver diferenças significativas para peso específico na condução de sua pesquisa.

Devido ao aumento dos níveis de inclusão do cálcio dietético na ração, o peso específico, o peso de casca e a porcentagem de casca e de cálcio nas excretas foram maximizados ao nível de 3,5\% de cálcio (Tabela 5). Entretanto, os níveis crescentes desse mineral na dieta promoveram redução linear no peso de gema, tendo essa variável 2,0\% de cálcio como nível satisfatório. Esses resultados corroboram aos relatados por Costa et al. (2007), que citam em suas pesquisas que o peso e a percentagem de casca, além do peso específico dos ovos, sofreram influência dos

Tabela 6 - Qualidade dos ovos e porcentagem de cálcio, fósforo e cinzas na excreta de codornas japonesas alimentadas com dietas com diferentes níveis de fósforo disponível

\begin{tabular}{|c|c|c|c|c|}
\hline \multirow[t]{2}{*}{ Item } & \multicolumn{2}{|c|}{$\begin{array}{l}\text { Nível de fósforo } \\
\text { disponível (\%) }\end{array}$} & \multirow[t]{2}{*}{$\begin{array}{l}\text { Valor } \\
\text { de P }\end{array}$} & \multirow[t]{2}{*}{$\mathrm{CV} \%$} \\
\hline & 0,15 & 0,35 & & \\
\hline Ovos viáveis/ave-dia (\%) & 78,95 & 77,14 & ns & 11,1 \\
\hline \multicolumn{5}{|c|}{ Ovos viáveis/ } \\
\hline ave-alojada(\%) & 75,08 & 75,74 & ns & 12,0 \\
\hline Peso específico (g/cm3) & 1,0687 & 1,0691 & ns & 0,13 \\
\hline Peso de casca (g) & 0,966 & 0,977 & ns & 3,9 \\
\hline Casca $(\%)$ & 7,77 & 7,86 & ns & 2,8 \\
\hline Peso de albúmen (g) & 7,60 & 7,62 & ns & 3,5 \\
\hline Albúmen (\%) & 60,98 & 61,04 & ns & 1,5 \\
\hline Peso de gema (g) & 3,88 & 3,87 & ns & 3,9 \\
\hline Gema $(\%)$ & 31,10 & 30,79 & ns & 2,8 \\
\hline Altura dos ovos (mm) & 33,63 & 33,58 & ns & 1,7 \\
\hline Diâmetro dos ovos (mm) & 25,60 & 25,64 & ns & 1,2 \\
\hline Ca excretado (\%) & 3,97 & 4,25 & ns & 9,3 \\
\hline Pt excretado (\%) & $0,81 b$ & $1,43 a$ & $\mathrm{P}<0,01$ & 10,9 \\
\hline $\begin{array}{l}\text { Matéria mineral } \\
\text { excretada }(\%)\end{array}$ & 28,08 & 27,43 & ns & 3,5 \\
\hline
\end{tabular}

ns $=$ não-significativo $(\mathrm{P}>0,05)$. níveis de cálcio na dieta. Igualmente, os níveis de cálcio e de fósforo disponível também não influenciaram a percentagem e o peso de albúmen dos ovos.

Os dois níveis de fósforo disponível influenciaram $(\mathrm{P}<0,01)$ apenas a percentagem do Pt excretado (Tabela 6). Portanto, o menor nível de fósforo disponível testado $(0,15 \%)$ se mostrou satisfatório na promoção de melhorias das características externas e internas dos ovos de codornas japonesas em postura, além de ter proporcionado menor poluição ambiental devido à menor excreção do $\mathrm{P}$ fítico. Entretanto, Costa et al. (2007), trabalhando com codornas de postura no período compreendido entre 61 a 145 dias de idade, observaram que os níveis de fósforo disponível influenciaram de forma quadrática a altura e o diâmetro médio dos ovos. Os autores também relatam que, com o aumento dos níveis de fósforo disponível na dieta, a percentagem e o peso de gema reduziram-se até os níveis $0,40 \%$ e $0,25 \%$ de $\mathrm{Pd}$, respectivamente.

Durante o período de coleta total das excretas, monitorou-se o consumo em gramas por ave dia e a sobra de ração em cada unidade experimental, além do teor em gramas excretado de ambos os minerais para posterior cálculo e análise descritiva da porcentagem do cálcio e do P retido no organismo das aves (Tabela 7).

Observa-se tendência (Tabela 7) de que, para um mesmo nível de fósforo disponível dietético (0,15\%), e mesmo nível de vitamina $\mathrm{D}$, quanto menor o percentual de cálcio na dieta, maior o seu percentual retido.

Pelo fato de a vitamina D, ou colecalciferol, ser um composto semelhante aos esteroides e essencial para a absorção de cálcio no trato gastrintestinal, esta, na sua forma ativa (calcitriol), estimula a síntese da proteína ligadora de cálcio, calbindin ( $\mathrm{CaBP}$ ), necessária ao transporte intracelular do cálcio.

Fisiologicamente, o comportamento experimental citado anteriormente pode ser explicado pelo fato de que, quando o cálcio é fornecido em níveis baixos na dieta, há maior produção da (CaBP), aumentando a eficiência de absorção e melhorando o aproveitamento do cálcio. No entanto, essa melhora ocorre até determinado nível, a partir do qual a elevação dos teores de cálcio (excesso de cálcio na dieta) reduz a absorção, comprovando que, sob baixa disponibilidade, há maior eficiência de utilização desse mineral (Dell’Isola \& Baião, 2001). Dessa forma, conclui-se que, quanto maior a relação necessidade/ingestão, maior será a taxa de absorção, por isso a absorção de cálcio está diretamente relacionada com a produção.

Ressalta-se que a relação Ca:Pd variou de 13,3:1 a 23,3:1, quando se fixou $0,15 \%$ de fósforo disponível dietético. Também é conhecido que poedeiras mais velhas 
Tabela 7 - Balanço mineral do cálcio e do fósforo, com base na matéria seca, em codornas japonesas com 57 semanas de idade (valores expressos em ave-dia)

\begin{tabular}{|c|c|c|c|c|c|c|c|c|}
\hline \multicolumn{9}{|c|}{ Balanço mineral do cálcio (Ca) e do fósforo (P) } \\
\hline Trat. Ca/Pd & $\begin{array}{c}\text { Ca ingerido } \\
\text { (g) }\end{array}$ & $\begin{array}{l}\text { Pt ingerido } \\
\text { (g) } 1\end{array}$ & $\begin{array}{c}\text { Ca excretado } \\
\text { (g) }\end{array}$ & $\begin{array}{l}\text { Pt excretado } \\
(\mathrm{g})\end{array}$ & $\begin{array}{c}\text { Ca retido } \\
(\mathrm{g})\end{array}$ & $\begin{array}{c}\% \text { Ca retido } \\
\text { (g) }\end{array}$ & $P$ retido & $\% \mathrm{P}$ retido \\
\hline $2,0 / 0,15$ & 0,466 & 0,082 & 0,200 & 0,067 & 0,266 & 0,015 & 57,08 & 18,29 \\
\hline $2,5 / 0,15$ & 0,500 & 0,071 & 0,248 & 0,058 & 0,252 & 0,013 & 50,40 & 18,31 \\
\hline $3,0 / 0,15$ & 0,674 & 0,081 & 0,354 & 0,065 & 0,320 & 0,016 & 47,48 & 19,75 \\
\hline $3,5 / 0,15$ & 0,718 & 0,073 & 0,367 & 0,059 & 0,351 & 0,014 & 48,89 & 19,18 \\
\hline $2,0 / 0,35$ & 0,394 & 0,109 & 0,166 & 0,091 & 0,228 & 0,018 & 57,87 & 16,51 \\
\hline $2,5 / 0,35$ & 0,506 & 0,120 & 0,236 & 0,104 & 0,270 & 0,016 & 53,36 & 13,33 \\
\hline $3,0 / 0,35$ & 0,603 & 0,120 & 0,330 & 0,102 & 0,273 & 0,018 & 45,27 & 15,00 \\
\hline $3,5 / 0,35$ & 0,704 & 0,118 & 0,399 & 0,104 & 0,305 & 0,014 & 43,32 & 11,86 \\
\hline
\end{tabular}

${ }^{1}$ Para o cálculo da ingestão de P (Pd), foram utilizados os valores de Pt da dieta, 0,357\%

tendem a diminuir a capacidade de absorção do cálcio intestinal, devido à redução na atividade da proteína ligadora de cálcio. Costa et al. (2007) demonstraram em suas pesquisas que aves que receberam dietas contendo 3,2\% de cálcio depositaram menos cálcio na casca dos ovos quando comparadas com aves que receberam 2,5\% de cálcio dietético. E essa redução equivale a 9,1\% a menos na deposição do cálcio da casca, o que significa que aves que recebem $2,5 \%$ de cálcio na dieta depositam 2,73\% a mais desse mineral na casca dos ovos produzidos. É importante mencionar que esses mesmos autores, ao avaliarem o teor de $\mathrm{P}$ na casca, encontraram praticamente o mesmo resultado para ambos os níveis de cálcio mencionados anteriormente, porém com ligeira tendência de maior deposição de $\mathrm{P}$ no nível de 2,5\% de cálcio dietético.

Quanto menor o nível do cálcio dietético em dietas formuladas com $0,35 \%$ de Pd, maior será o percentual de fósforo retido (Tabela 7). O inverso também é verdadeiro: quanto maior o nível do cálcio dietético em uma dieta formulada com $0,35 \%$ de Pd, menor será o percentual do P retido. O mesmo comportamento foi verificado para a retenção do cálcio para o mesmo nível de fósforo disponível $(0,35 \%)$ na dieta.

Se considerarmos que um ovo de codorna pesa cerca de 12,0 g e que a casca representa em média $8 \%$ de seu peso total, então podemos afirmar que o peso da casca equivale a $0,96 \mathrm{~g}$. Se $30 \%$ do peso da casca é devido ao teor de cálcio nela contido (Costa et al. (2007)), logo seriam necessários apenas 0,288 g de cálcio para a formação da casca de um ovo por dia. Levando-se em consideração que o ovo de codorna pese em torno de $11 \mathrm{~g}$ após a retirada da casca (0,96 g), e que o ovo tem em média, como composição nutricional, 8,7 mg de cálcio e 30,7 mg de fósforo, obtendo uma relação P:Ca de 3,5:1 teremos o total de 0,297 g de cálcio, o que equivale ao teor total de cálcio necessário para a produção de um único ovo. Somado a isso, sabemos que aproximadamente 99\% do cálcio distribuído no organismo estão presentes nos ossos e que estes também contribuem fisiologicamente para a formação da casca por meio da reabsorção óssea.

Considerando nos resultados (Tabela 7), pode-se inferir que os níveis de cálcio testados foram eficientes em atender à demanda por cálcio dietético para a produção dos ovos, uma vez que as aves se encontravam em declínio de postura e, devido à contribuição do cálcio ósseo na formação da casca, este é considerado um comportamento naturalmente fisiológico. É necessário relatar que houve quantidade suficiente de cálcio dietético para os maiores níveis de cálcio (3,0\% e 3,5\%) associados ao menor nível de fósforo disponível (0,15\%), evitando-se maior mobilização do cálcio ósseo em direção à calcificação da casca durante a formação do ovo.

Entretanto, o fato de o valor de retenção do cálcio (g) obtido pelas aves que receberam dietas contendo $2,0 \%$ de cálcio e 0,35\% de fósforo disponível ter sido razoavelmente inferior ao requerido para a produção de um ovo ave-dia (0,297 g de Ca) deve-se ao menor consumo de ração obtido por essas aves, o que contribuiu com a redução da ingestão do cálcio dietético.

\section{Conclusões}

De acordo com os resultados obtidos neste experimento, níveis dietéticos de 3,5\% de cálcio e 0,15\% de fósforo disponível são suficientes para proporcionar bom desempenho produtivo e manutenção satisfatória da qualidade dos ovos de codornas japonesas no terço final do ciclo de postura (45 a 57 semanas de idade) e correspondem a um consumo diário de 899 mg de cálcio e $40 \mathrm{mg}$ de fósforo disponível por ave.

\section{Referências}

BARRETO, S.L.T.; PEREIRA, C.A.; UMIGI, R.T. et al. Determinação da exigência nutricional de cálcio de codornas 
japonesas na fase inicial do ciclo de produção. Revista Brasileira de Zootecnia, v.36, n.1, p.68-78, 2007.

BRANDÃO, P.A.; COSTA, F.G.P.; SILVA, J.H.V. et al. Exigência de cálcio para codornas japonesas (coturnix coturnix japonica) em postura. Acta Scientiarum, v.29, n.1, p.17-21, 2007.

COSTA, C.H.R.; BARRETO, S.L.; MOURA, W.C.O. et al. Níveis de fósforo e cálcio em dietas para codornas japonesas em postura. Revista Brasileira de Zootecnia, v.36, n.6, p.2037-2046, 2007 (supl.).

DELL'ISOLA, A.T.P.; BAIÃO, N.C. Cálcio e fósforo para galinhas poedeiras - Avicultura. Caderno Técnico de Veterinária e Zootecnia, n.34, p.65-92, 2001.

GARCIA, J.; MURAKAMI, A.E.; MARTINS, E.N. et al. Exigências nutricionais de cálcio e fósforo para codornas japonesas (Coturnix coturnix japonica) em postura. Acta Scientiarum, v.22, n.3, p.733-739, 2000.

GARCIA, E.A.; PIZZOLANTE, C.C. Nutrição de codornas para postura. In: SIMPÓSIO INTERNACIONAL DE COTURNICULTURA, 2., 2004. Anais... Lavras: Universidade Federal de Lavras, 2004. (CD-ROM).

HAMILTON, R.M.G. Methods and factors that affect the measurement of egg shell quality. Poultry Science, v.61, p.2022-2039, 1982.

KADAM, M.M.; MANDAL, A.B.; ELANGOVAN, A.V. et al. Response of laying Japanese quail to dietary calcium levels at two levels of energy. Journal of Poultry Science, v.43, p.351-356, 2006.

LEANDRO, N.S.M.; JARDIM FILHO, R.M.; BRITO, A.B.; et al. Granulometria do calcário no desempenho e qualidade da casca de ovos de codornas japonesas. Ciência Animal Brasileira, v.7, n.4, p.381-387, 2006.

MASUKAWA, Y.; FERNANDES, E.B.; MORAES, V.M.B. et al. Níveis de cálcio da dieta sobre o desempenho e a qualidade da casca de ovos de codornas japonesas. Ars Veterinária, v.17, n.2, p.144-148, 2001.

MOURA, G.S.; BARRETO, S.L.T.; DONZELE, J.L. et al. Dietas de diferentes densidades energéticas mantendo constante a relação energia metabolizável:nutrientes para codornas japonesas em postura. Revista Brasileira de Zootecnia, v.37, n.9, p.1628-1633, 2008.
NATIONAL RESEARCH COUNCIL - NRC. Nutrient requirements of poultry. 9.ed. Washington, D.C.: National Academy of Sciences, 1994. 155p.

PEDROSO, A.; MORAES, V.M.B.; ARIKI, J. et al. Efeito de níveis dietéticos de cálcio e fósforo disponível sobre o desempenho e qualidade dos ovos de codornas japonesas. Ars Veterinária, v.15, n.2, p.135-139, 1999.

PINTO, R.; FERREIRA, A.S.; DONZELE, J.L. et al. Exigência de metionina mais cistina para codornas japonesas em postura. Revista Brasileira de Zootecnia, v.32, n.5, p.1166-1173, 2003a.

PINTO, R.; FERREIRA, A.S.; DONZELE, J.L. et al. Exigência de lisina para codornas japonesas em postura. Revista Brasileira de Zootecnia, v.32, n.5, p.1182-1189, 2003b.

PINHEIRO, R.T.; BARRETO, S.L.; DONZELE, J.L. et al. Níveis de treonina digestível em dietas para codorna japonesa em postura. Revista Brasileira de Zootecnia, v.36, n.6, p.1868-1874, 2008.

PIZZOLANTE, C.C.; SALDANHA, E.S.P.B.; GARCIA, E.A. et al. Efeito do horário de fornecimento de rações contendo diferentes níveis de cálcio sobre o desempenho produtivo e qualidade de ovos de codornas japonesas (Coturnix japonica) em final de produção. Revista Ciência Animal Brasileira, v.8, n.4, p.677-683, 2007.

SILVA, D.J. Análises de alimentos (métodos químicos e biológicos). Viçosa, MG: Universidade Federal de Viçosa, 1998. 166p.

SILVA, J.H.V.; COSTA. F.G.P.; SILVA, E.L. et al. In : SIMPÓSIO INTERNACIONAL, 3.; CONGRESSO BRASILEIRO DE COTURNICULTURA - EXIGÊNCIAS NUTRICIONAIS DE CODORNAS, 2., 2007, Lavras. Anais... UFLA, 2007. p.44-64.

SULTANA, F.; ISLAN, M.S.; HOWLIDER, M.A.R. Effect of dietary calcium sources and levels on egg production and egg quality of Japanese quail. International Journal of Poultry Science, v.6, p.131-136, 2007.

UMIGI, R.T.; BARRETO, S.L.; DONZELE, J.L. et al. Níveis de treonina digestível em dietas para codorna japonesa em postura. Revista Brasileira de Zootecnia, v.36, n.6, p.1868-1874, 2007.

UNIVERSIDADE FEDERAL DE VIÇOSA - UFV. Central de Processamento de Dados (UFV/CPD). Manual de utilização do programa SAEG (Sistema para Análises Estatísticas e Genéticas). Viçosa, MG: UFV, 2004. 59p.

YAKOUT, H.M. Calcium and phosphorus requirements of Japanese quail hens during the early production period. Egyptian Poultry Science Journal, v.23, p.617-628, 2004. 